\title{
Amorós Negre, Carla. Las lenguas en la sociedad. Madrid: Síntesis, 2014. $231 \mathrm{pp}$.
}

El evidente impulso de orientaciones centradas en la dimensión cognitiva del lenguaje, muchas veces apoyadas en metodologías cuantitativas y en marcos conceptuales que olvidan el lugar de los hablantes, de la creatividad y de lo que los usuarios hacen con su lengua cuando se comunican, puede llevar a pensar que el futuro de la investigación está en esos ámbitos o anda por esos caminos. No faltará quien crea ver en ella la única expresión posible de una lingüística moderna, seria, "dura”, científica, o, como se dice hoy, interdisciplinaria. Pero se trata de un espejismo ocasionado por la difusión de esos marcos teóricos y recursos metodológicos, marcos y recursos que han terminado reduciendo el quehacer a un tipo de exploración y, en ocasiones, han logrado erigirse en representantes de toda la disciplina, dejando fuera a otras orientaciones analíticas y a investigadores motivados por otra manera de preguntarse sobre el lenguaje, las lenguas y el habla. En ese contexto, debe considerarse que la crítica social y la memoria histórica no gozan actualmente de buena prensa ni son favorecidos por el mercado ni por las instituciones que administran fondos de investigación, hechos que resienten a las ciencias humanas en general, les angosta posibilidades y presencia académica y profesional, y favorecen corrientes que postergan el interés por la dimensión social e histórica de los fenómenos verbales.

Pues bien, el libro de Carla Amorós pone las cosas en el otro plato de la balanza y, como si se tratara de un efecto rebote, desde ahí amplifica otro campo de trabajo, otras preguntas y otros intereses, muchos de ellos tan modernos como los aludidos o tan antiguos como la reflexión del hombre sobre la lengua que hereda de la madre. Quiero decir: este libro concentra el interés en la dimensión 
social de la lengua. Su espacio es, así, distinto del que promueve el mercado. Lo explicita el título, por cierto, pero lo confirma el lector en las 231 páginas que constituyen el ensayo. Visto así, es claro que Amorós toma partido por la dimensión fenomenológica y política de la lengua porque huye de planteamientos que alejan la reflexión y el estudio de los hablantes del equilibrio y de la variación en que existe y se manifiesta toda lengua humana o que llevan a olvidar la trascendencia que tiene, para la conciencia lingüística y para la percepción de los fenómenos verbales, la imposición de modelos y la propagación de juicios y valoraciones en torno a formas y maneras particulares de hablar español. Precisamente, son estos los temas que desarrolla este trabajo. Puede decirse que a Amorós le interesa el habla, antes que la lengua en sentido mental y abstracto; pero le interesa la lengua en tanto saber social e histórico, antes que el habla como hecho individual y aislado. El libro es un permanente juego de contrapesos entre esas dos porciones del lenguaje. Amorós consigue armonizar ambos extremos y tiene la prudencia de no dejarse seducir por la pretensión de agotar la complejidad inherente a uno y a otro extremo y opta, más bien, por señalar los aspectos, los problemas y la terminología, con sus idas y venidas, y sus vacíos, involucrados en cada uno de los tópicos que desarrolla en su trabajo.

Como, en términos generales, el libro pretende despertar el interés por los temas que desarrolla en seis capítulos y como, seguramente, la autora tuvo en mente un público lector integrado por estudiantes, cada capítulo termina con preguntas, ejemplos, tareas que redondean e invitan a profundizar algún punto tratado en las páginas precedentes. Los títulos de los capítulos dan cuenta de inmediato de la actualidad de algunos temas y, en otros casos, a mi juicio, inciden en tópicos que el interesado por la dimensión social de las lenguas no debería prescindir porque, aunque conocidos, sirven para precisar conceptos y para tener claridad sobre los vaivenes que habitualmente sufren los términos científicos. Así, pues, el primer capítulo lleva el título de "Lenguaje y sociedad: conceptos"; el segundo, "De la lingüística tradicional a la lingüística moderna: 
la prescripción encubierta"; el tercero, "El lugar de la prescripción en la lingüística moderna: política y planificaciones lingüísticas"; el cuarto, "La construcción social de las lenguas: la normativa y la estandarización lingüísticas"; el quinto, "En busca del estándar"; finalmente, el sexto, "La concepción del español como lengua pluricéntrica". Obviamente concluye la obra con una útil bibliografía que reúne un acervo adecuado y nutrido de publicaciones sobre los temas incluidos en cada capítulo.

De los seis capítulos, el quinto y el sexto convergen con más claridad en la misma línea argumental y se alimentan recíprocamente en su desarrollo. Ello se explica porque la reflexión sobre el carácter pluricéntrico del español implica la valoración del estándar y viceversa. Quiero decir que no es posible distinguir ambos conceptos cuando el marco analítico recae sobre el español y probablemente tampoco en el caso de otras lenguas, aunque tengan sus respectivos alcances y justificaciones. Por ello, parece sensato discutir previamente el concepto de lengua estándar y, en otro momento, aplicarlo al mundo hispanohablante. Pienso que ambos temas tienen hoy especial relevancia. La autora ofrece una adecuada presentación de las discusiones existentes en torno a la idea de estándar y pone sobre la mesa los límites descriptivos del pluricentrismo. Como se sabe, este último tema ha despertado especial simpatía en círculos académicos, europeos y americanos. Pero, como muchas veces sucede con los entusiasmos y con los conceptos que se difunden con rapidez, me parece necesario moderar los impulsos y disminuir la prisa para evitar que los términos y los propósitos terminen siendo desvirtuados o convertidos en etiquetas vacías aplicables a cualquier expresión singular o a simples y habituales hechos de variación lingüística. Hoy, al margen de matices, la realidad pluricéntrica del español es un hecho aceptado. Hay un extendido y justificado consenso en torno suyo. Esa valoración pone en pie de igualdad situaciones y contextos sociolingǘsticos distintos, admite la diversidad y enfatiza la dimensión histórica y social de las lenguas como procesos que desembocan en centros irradiadores de usos y modalidades que gozan de mayor (o de menor) prestigio entre los hablantes 
de una lengua histórica. En los capítulos quinto y sexto, Amorós ofrece el complejo panorama existente alrededor de estos temas y conceptos. Visto el asunto desde Hispanoamérica, la discusión viene - finalmente- a reconocer modalidades lingüísticas antes sujetas a prejuicios y consideraciones negativas, por lo general observadas desde las alturas de un centro normativo europeo, ajeno a la vida, a los contextos y las culturas que han definido la realidad sociolingüística del español americano. Pero, con la adhesión que despierta este marco, debe darse un afinamiento conceptual que permita una descripción segura y racional de los fenómenos, en particular, que permita determinar qué debe entenderse por centro prestigioso y, claro, que permita decirnos dónde está. No es tema fácil. Fácil es afirmarlo; también es fácil empaquetar el término en un discurso reivindicatorio e ideológico. Lo difícil es su demostración científica. Este libro puede servirnos para evitar que la discusión se descarrile y se pierda el paso que exige asumir que el español existe en su diversidad. En suma, Carla Amorós ofrece un libro útil, interesante, cuya lectura debe ser alentada y cuyo contenido permite entender una discusión actual, moderna y necesaria.

Carlos Garatea G. Pontificia Universidad Católica del Perú

Recibido: 25/09/2017 Aceptado: 01/11/2017 